\title{
Hygienic Practice during Complementary Feeding and Associated Factors among Mothers of Children Aged 6-24 Months in Bahir Dar Zuria District, Northwest Ethiopia, 2019
}

\author{
Alelign Alemu Demmelash $\left(\mathbb{D},{ }^{1}\right.$ Biruk Demissie Melese, ${ }^{2}$ Fitalew Tadele Admasu, ${ }^{3}$ \\ Eniyew Tegegne Bayih, ${ }^{4}$ and Getachew Yideg Yitbarek $\mathbb{1}^{5}$ \\ ${ }^{1}$ Department of Environmental Health and Hygiene, Bonn Universiy Hospital, Bonn, Germany \\ ${ }^{2}$ Deprtmenet of Public Health, College of Health Science, Debre Tabor University, Debre Tabor, Ethiopia \\ ${ }^{3}$ Deprtmenet of Biomedical Sciences (Medical Biochemistry), College of Health Science, Debre Tabor University, \\ Debre Tabor, Ethiopia \\ ${ }^{4}$ Deprtmenet of Environmental Health, College of Health Science, Debre Markos University, Debre Markos, Ethiopia \\ ${ }^{5}$ Deprtmenet of Biomedical Sciences (Medical Physiology), College of Health Science, Debre Tabor University, \\ Debre Tabor, Ethiopia
}

Correspondence should be addressed to Alelign Alemu Demmelash; alemualelign@gmail.com

Received 10 February 2020; Accepted 20 May 2020; Published 20 June 2020

Academic Editor: Issam A. Al-Khatib

Copyright (c) 2020 Alelign Alemu Demmelash et al. This is an open access article distributed under the Creative Commons Attribution License, which permits unrestricted use, distribution, and reproduction in any medium, provided the original work is properly cited.

\begin{abstract}
Introduction. Breast milk alone is no longer sufficient to meet the nutritional requirements of infants, and therefore food is needed. Microbiologically contaminated food is particularly harmful for children $<2$ years of age. There is scanty of information on hygienic practice and associated factors during complementary feeding among mothers of children aged 6 to 24 months in the country, particularly in the study setting. Objective. The study was aimed to assess hygienic practices and associated factors during complementary feeding among children aged 6 to 24 months in Bahir Dar Zuria District, Northwest Ethiopia. Methods. A community-based cross sectional study was conducted from March 20 to April 20, 2019. A multistage sampling technique was used to select the study participants. Data were collected using the structured interviewer administered questionnaire. Bivariable and multivariable logistic regression analyses were used to identify the factors associated with hygienic practice during complementary feeding. Data were entered by using Epi Data version 3.1, and then it was exported to SPSS version 21 for analysis, and at $95 \%$ CI, $p$ value $<0.05$ was considered statistically significant. Result. Among 604 respondents, 235 (38.9\%) of study participants had good hygienic practice during complementary feeding. Access to media (AOR: 8.8, 95\% confidence interval (CI): 3.8-20.3), private latrine ownership (AOR: 4.11,95\% CI: 1.90-8.49), presence of hand washing facility at doorstep (AOR: 6.75 95\% CI: 3.16-14.41), and residence of the study participants (AOR: 85.42, 95\% CI: 1.94-15.2) were significantly associated with good hygienic practice of mothers during complementary feeding. Conclusion. Majority of mothers had poor hygienic practice during complementary feeding. Attitude of mothers, access to media, household private latrine ownership, presence of handwashing facility, and residence of the study participants were significantly associated with hygiene practice of mothers during complementary feeding. The health sector should train mothers on good hygiene practices during complementary feeding.
\end{abstract}

\section{Introduction}

Complementary feeding is the process that starts when breast milk alone is no longer sufficient to meet the nutritional requirements of infants and therefore food is needed, along with breast milk. Complementary foods in resource-poor settings can result in diets that are microbiologically unsafe, which can lead to the risk of exposure to food-borne pathogens [1]. Microbiologically contaminated food is particularly harmful for children aged $<2$, who have 
immature immune systems and are vulnerable to infections with enteric pathogens [2].

Poor food hygiene practice is one of the major contributors to childhood diarrhea up to $70 \%$ of diarrhea episodes in developing countries [3]. Poor sanitation, unsafe water supplies, and poor personal hygiene are responsible for $88 \%$ of childhood deaths [4]. Recent evidence indicated that weaning foods prepared in unhygienic conditions can be highly contaminated by pathogens and are a major cause of diarrhea and associated malnutrition [5]. It has been estimated that $50 \%$ of child under nutrition may be attributable to poor WASH practices [6]. Children are particularly vulnerable to infections at the weaning period, and poor complementary food hygiene practice and subsequent diarrhea may contribute to stunting [7].

Contamination of complementary foods is very common in developing countries due to contaminated water, poor personal hygiene, inadequate cleaning of eating utensils and inappropriate storage of foods after preparation [8], inadequate knowledge of safe food handling, poor environmental sanitation, and inadequate social amenities such as toilets, kitchen, and poor sewage systems [9]. Appropriate complementary feeding (CF) is an important determinant for the achievement of healthy growth and survival of young children in their early years of life. It has a potential to prevent $6 \%$ of all under-five deaths, particularly in the developing world [10]. Improving home handwashing practices remains one of the central challenges for the public health in the 21 st century. Each year, over 5 million children in developing countries die from either diarrhea or acute respiratory infections [11].Globally handwashing with soap at key times is as low as 2 to 35\% [12]. An average of $65 \%$ of death caused by diarrheal diseases could be reduced if good hygiene practice accompanies with the provision of water and sanitation [13].

A Vietnam study revealed that $36.8 \%, 29 \%$, and $43.2 \%$ of mothers always washed their hand with soap, after using toilet, before eating, and before feeding, respectively [14]. Another study conducted in Bangladesh illustrated that $17 \%$ of mothers did not wash their hands after defecation and $26 \%$ of mothers did not properly clean their hands and utensils before feeding [12].

The study performed in Northwest Ethiopia showed that mothers who received weaning advice tend to practice appropriate weaning than those who did not receive [15]. Another study conducted in rural Bangladesh found the presence of water and soap at the handwashing place, mother's education level, availability of water, and soap near to the toilet to be significantly associated with handwashing practices [16].

A similar study conducted in Bangladesh showed that latrine ownership, availability of handwashing materials such as ash or soap, and water availability near to latrine were associated with handwashing practice [17]. A study in India reported $59.4 \%$ of the participants used water and soap for cleaning their hands and $37 \%$ of them washed their hands with water and soap after defecation [18].

Improving food hygiene practices play a great role in child growth and development. Previous studies were focused on the time of weaning and the frequency and consistency of complementary feeding; however, hygienic practice during complementary feeding was not addressed. Therefore, the present study was aimed to assess the hygiene practice and associated factors during complementary feeding among mothers of children aged 6-24 months in Bahir Dar Zuria District, Northwest Ethiopia.

\section{Materials and Methods}

2.1. Study Area and Period. A community-based cross sectional study was conducted from March 20 to April 20, 2019, in Bahir Dar Zuria District, Northwest Ethiopia. The district is located at the distance of $564 \mathrm{~km}$ from the capital city Addis Ababa. There are 36 kebeles with a total population of 200,000. The district has 9 health centers and 36 health posts.

2.2. Population and Eligibility Criteria. All lactating mothers who reside in the district were the source population while lactating mothers with children aged 6-24 months old and who were present during the data collection period were the study population. All mothers with children aged 6-24 months were included, while mothers who were seriously ill and unable to hear were excluded from the study.

2.3. Sample Size Determination and Sampling Technique. The sample size was determined using the single population proportion formula with the following assumptions: $95 \% \mathrm{CI}$, margin of error $(D=0.05)$, and proportion of hygienic practice about $50 \%$ since the prior researches did not mention the level of hygienic practice of mothers during complementary feeding. Considering the design effect of 1.5 and 5\% nonresponse rate, the final sample size was 604 . The multistage sampling technique was used to get the study participants. In Bahir Dar Zuria District, there are a total of 36 kebeles. Among these, ten kebeles were selected randomly. The sample size was proportionally allocated to each selected kebeles based on the size of the population in the kebeles. The list of study participants by their name and residence was found from health posts and the health centers. After this, six villages were selected in each selected kebeles (a total of 60 villages), and all mothers with children aged 6-24 months were included in the study, and the data were collected.

2.4. Data Collection Procedure. An interviewer-administered semistructured questionnaire was used to assess the hygienic practice of mothers during complementary feeding. The data were collected by ten health extension workers under the supervision of investigators (supervisors). The data were checked for any incompleteness and coding error and then entered into Epi Data version 3.1 software, and finally, it was exported to SPSS software for analysis.

2.5. Operational Definition. Good hygienic practice was defined as a score of $\geq 75 \%$, and poor hygienic practice as a score of $<75 \%$ [12]. 
2.6. Data Analysis. Descriptive statistics such as frequencies, proportions, and numerical summary measures were used. The data were analyzed using statistical package SPSS version 21 software. Bivariable and multivariable logistic regression analyses were done, and the results were presented by using tables. The $P$ value less than 0.2 in the bivariable regression was considered as eligible for the multivariable logistic regression analysis. Statistically significant association was measured by using the adjusted odds ratio (AOR) with $95 \%$ confidence interval, and $p$ value $<0.05$ was considered as statistically significant.

2.7. Data Quality Management. Data quality was ensured through training of data collectors, close supervision, prompt feedback, and review of each of the completed questionnaires daily. One-day training was given for data collectors about the administration of each question and ethical principles before starting the data collection. Daily supervision was done by the supervisors to check the completeness and reliability of the data. The principal investigator was also checking the data consistency and completeness during data collection, data entry, and analysis.

2.8. Ethical Consideration. The study was conducted after getting the ethical approval from the institutional review board of Bahir Dar University, informed consent was obtained from mothers having children aged 6-24 months, and the confidentiality of the information taken from the study participants was maintained.

\section{Result}

3.1. Sociodemographic Characteristics of the Respondents. A total of 604 study participants were interviewed. The mean age of the respondents (mothers) was $28.3 \pm \mathrm{sd}$ 4.4.The majority (593 (98.2\%)) of the respondents were orthodox, and 601 (99.5\%) of the respondents were Amhara in their ethnicity. $342(56.6 \%)$ of mothers were unable to read and write, and 338 (56\%) mothers were house wives as illustrated in Table 1:

\subsection{Hygienic Practice of the Respondents during Comple-} mentary Feeding. Among 604 respondents, 38.9\% of study participants had good practice during complementary feeding. Only 56 (9.3\%) of the respondents washed their hands with soap after toilet and majority of them (393 $(65.1 \%))$ washed only with water after toileting. 54 (8.9\%) respondents always washed their hands with soap and water before feeding, and $424(70.2 \%)$ respondents washed their hands only with water. 97 (16.1\%) study participants always washed their food utensils with water and soap, and 475 (78.6\%) participants have separate utensils for raw and cooked foods.

In the present study, $46.2 \%$ of the respondents had handwashing facility after toileting, and among those, $33.2 \%$ of the respondents' used soap or ash with water at
TABLE 1: Sociodemographic characteristics of the respondents, in Bahir Dar Zuria District, Northwest Ethiopia, 2019.

\begin{tabular}{|c|c|c|}
\hline Variables & Total $(n)$ & Percent \\
\hline \multicolumn{3}{|l|}{ Age of mothers } \\
\hline $20-24$ & 116 & 19.2 \\
\hline $25-29$ & 247 & 40.9 \\
\hline $30-34$ & 175 & 29 \\
\hline$\geq 35$ & 66 & 10.9 \\
\hline \multicolumn{3}{|l|}{ Ethnicity } \\
\hline Amhara & 601 & 99.5 \\
\hline Tigray & 3 & 0.5 \\
\hline \multicolumn{3}{|l|}{ Mother's educational status } \\
\hline Unable to read and write & 342 & 56.6 \\
\hline Able to read and write & 170 & 28.1 \\
\hline Primary schooled & 77 & 12.7 \\
\hline Secondary school and above & 15 & 2.5 \\
\hline \multicolumn{3}{|l|}{ Mother's occupation } \\
\hline House wife & 338 & 56 \\
\hline Merchant & 29 & 4.8 \\
\hline Farmer & 230 & 38.1 \\
\hline Daily laborer & 7 & 1.2 \\
\hline \multicolumn{3}{|l|}{ Husband's educational status } \\
\hline Unable to read and write & 402 & 66.6 \\
\hline Able to read and write & 135 & 22.4 \\
\hline Primary schooled & 51 & 8.4 \\
\hline Secondary school and above & 16 & 2.6 \\
\hline \multicolumn{3}{|l|}{ Husband's occupation } \\
\hline Farmer & 575 & 95.2 \\
\hline Merchant & 20 & 3.3 \\
\hline Daily laborer & 9 & 1.5 \\
\hline \multicolumn{3}{|l|}{ Residence } \\
\hline Rural & 507 & 83.9 \\
\hline Urban & 97 & 16.1 \\
\hline
\end{tabular}

the handwashing facility. $27.8 \%$ of the respondents used water treatment solution (Wuha Agar) whereas $45.5 \%$ of the respondents did not use any water treatment method (Table 2).

3.3. Factors Associated with Hygienic Practice of the Respondents during Complementary Feeding. Factors associated with hygienic practice during complementary feeding were described by using bivariable and multivariable logistic regression in Table 3. Hygienic practice during complementary feeding was significantly associated with the residence of the respondents.

Mothers who live in the urban area were 5-folds (AOR: 5.42, 95\% CL:1.94-15.2) more likely to practice hygienic preparation of complementary food as compared with those who live in rural. Respondents who were accessed to media such as television or radio were 9-folds (AOR: 8.8, 95\% CL: 3.8-20.3) more likely to carry out hygienic practice during complementary feeding than respondents who were not accessed to media, and those respondents who had private latrine were 4-folds (AOR: 4.11, 95\% CL: 1.90-8.49) more likely to perform good hygienic practice during complementary feeding, as compared with their counterparts. 
Table 2: Hygienic practice of the respondents, during complementary feeding in Bahir Dar Zuria District, Northwest Ethiopia, 2019.

\begin{tabular}{|c|c|c|}
\hline Variables & Total $(n)$ & Percent \\
\hline \multicolumn{3}{|l|}{ Mothers handwashing with soap after toilet } \\
\hline Always water with soap & 56 & 9.3 \\
\hline Not always water with soap & 94 & 15.6 \\
\hline Wash only with water & 393 & 65.1 \\
\hline Do not wash & 61 & 10.1 \\
\hline \multicolumn{3}{|l|}{ Mothers handwashing with soap before feeding the child } \\
\hline Always water with soap & 54 & 8.9 \\
\hline Not always water with soap & 124 & 20.5 \\
\hline Wash only with water & 424 & 70.2 \\
\hline \multicolumn{3}{|l|}{ Handwashing with soap before food preparation } \\
\hline Always water with soap & 49 & 8.1 \\
\hline Not always water with soap & 109 & 18 \\
\hline Wash only with water & 446 & 73.9 \\
\hline \multicolumn{3}{|l|}{ Washing utensils } \\
\hline Always water with soap & 97 & 16.1 \\
\hline Not always water with soap & 171 & 28.3 \\
\hline Wash with ash & 336 & 55.6 \\
\hline \multicolumn{3}{|l|}{ Separating utensils for raw and cooked food } \\
\hline Yes & 475 & 78.6 \\
\hline No & 129 & 21.4 \\
\hline \multicolumn{3}{|l|}{ Children handwashing after toilet } \\
\hline Always water with soap & 145 & 24 \\
\hline Not always water with soap & 203 & 33.6 \\
\hline Do not wash & 256 & 42.4 \\
\hline \multicolumn{3}{|l|}{ Place of preparing foods for cooking } \\
\hline Cultural stove & 450 & 74.5 \\
\hline Modern stove & 154 & 25.5 \\
\hline \multicolumn{3}{|l|}{ Children handwashing before eating } \\
\hline Always water with soap & 123 & 20.4 \\
\hline Not always water with soap & 259 & 42.9 \\
\hline Did not wash & 122 & 36.8 \\
\hline \multicolumn{3}{|c|}{ Keep ready-to-eat food in clean containers and cover it properly } \\
\hline Always & 428 & 70.9 \\
\hline Not always & 176 & 29.1 \\
\hline \multicolumn{3}{|l|}{ Household has handwashing facility after toilet visit } \\
\hline Yes & 279 & 46.2 \\
\hline No & 325 & 53.8 \\
\hline \multicolumn{3}{|l|}{ Handwashing facility has soap or ash with water } \\
\hline Yes & 199 & 33.2 \\
\hline No & 405 & 66.8 \\
\hline \multicolumn{3}{|l|}{ Serve cooked food immediately for children } \\
\hline Yes (if served within two hours) & 571 & 94.5 \\
\hline No (if not served within two hours) & 33 & 5.5 \\
\hline \multicolumn{3}{|l|}{ Serve leftover food for children } \\
\hline Always serve leftover food & 10 & 1.7 \\
\hline Sometimes serve leftover food & 34 & 5.6 \\
\hline Never serve leftover food & 560 & 92.7 \\
\hline \multicolumn{3}{|l|}{ Mother's finger nail cut short } \\
\hline Yes & 498 & 82.5 \\
\hline No & 106 & 17.5 \\
\hline \multicolumn{3}{|l|}{ Presence of children's private feeding utensil } \\
\hline Yes & 303 & 50.2 \\
\hline No & 301 & 49.8 \\
\hline \multicolumn{3}{|l|}{ Children's private feeding utensils are clean } \\
\hline Yes (if they are washed thoroughly and look clean) & 295 & 48.8 \\
\hline No (if utensils are dusty and look dirty) & 309 & 51.2 \\
\hline \multicolumn{3}{|l|}{ Use of hot water for cleaning food utensils } \\
\hline Yes & 412 & 68.2 \\
\hline No & 192 & 31.8 \\
\hline Use soap or ash for washing food utensils & & \\
\hline
\end{tabular}


TABLE 2: Continued.

\begin{tabular}{|c|c|c|}
\hline Variables & Total $(n)$ & Percent \\
\hline Yes & 410 & 67.9 \\
\hline No & 194 & 32.1 \\
\hline \multicolumn{3}{|l|}{ Household has Private latrine } \\
\hline Yes & 310 & 51.3 \\
\hline No & 294 & 48.7 \\
\hline \multicolumn{3}{|l|}{ Source of drinking water } \\
\hline Piped water & 51 & 8.4 \\
\hline Well water & 202 & 33.4 \\
\hline River water & 115 & 19 \\
\hline Spring water & 236 & 39.1 \\
\hline \multicolumn{3}{|l|}{ Access to media (TV or radio) } \\
\hline Yes & 305 & 50.5 \\
\hline No & 299 & 49.5 \\
\hline \multicolumn{3}{|l|}{ Household drinking water treatment options } \\
\hline Chlorine & 92 & 15.2 \\
\hline Water treatment solution (Wuha Agar) & 168 & 27.8 \\
\hline Boiling & 69 & 11.4 \\
\hline No usage of treatment & 275 & 45.5 \\
\hline
\end{tabular}

TABLE 3: Bivariable and multivariable logistic regression analysis output of associated factors with hygienic practice of mothers during complementary feeding in Bahir Dar Zuria District, Northwest Ethiopia, 2019.

\begin{tabular}{|c|c|c|c|c|c|}
\hline \multirow{2}{*}{ Variable } & \multicolumn{2}{|c|}{ Practice } & \multirow{2}{*}{ COR $(95 \% \mathrm{CI})$} & \multirow{2}{*}{$\operatorname{AOR}(95 \% \mathrm{CI})$} & \multirow{2}{*}{$P$ value } \\
\hline & Good & Poor & & & \\
\hline \multicolumn{6}{|l|}{ Residence } \\
\hline Rural & $157(31 \%)$ & $350(69 \%)$ & 1.00 & 1.00 & \multirow{2}{*}{0.001} \\
\hline Urban & $78(80.4 \%)$ & $19(19.6 \%)$ & $9.15(5.3-15.6)$ & $5.42(1.94-15.2)$ & \\
\hline \multicolumn{6}{|c|}{ Access to media } \\
\hline Yes & $202(66.2 \%)$ & $103(33.8 \%)$ & $15.8(10.25-24.36)$ & $8.8(3.8-20.3)$ & \multirow{2}{*}{$<0.001$} \\
\hline No & $33(11 \%)$ & $266(89 \%)$ & 1.00 & 1.00 & \\
\hline \multicolumn{6}{|l|}{ Attitude } \\
\hline Negative & $54(19.7 \%)$ & $220(80.3 \%)$ & 1.00 & 1.00 & \multirow{2}{*}{$<0.001$} \\
\hline Positive & $181(54.8 \%)$ & $149(45.2 \%)$ & $4.95(3.42-7.15)$ & $4.01(1.9-8.5)$ & \\
\hline \multicolumn{6}{|c|}{ Presence of handwashing facility } \\
\hline Yes & $184(65.9 \%)$ & $95(34.1 \%)$ & $10.4(7.06-15.3)$ & $6.75(3.16-14.41)$ & \multirow{2}{*}{$<0.001$} \\
\hline No & $51(21.7 \%)$ & $274(84.3 \%)$ & 1.00 & 1.00 & \\
\hline \multicolumn{6}{|c|}{ Private latrine ownership } \\
\hline Yes & $201(64.8 \%)$ & $109(35.2 \%)$ & $14.1(9.2-21.6)$ & $4.11(1.90-8.49)$ & \multirow{2}{*}{$<0.001$} \\
\hline No & $34(11.6 \%)$ & $260(88.4 \%)$ & 1.00 & 1.00 & \\
\hline \multicolumn{6}{|l|}{ Age } \\
\hline $20-24 \mathrm{yr}$ & $68(58.6 \%)$ & $48(41.4 \%)$ & $7.08(3.36-14.9)$ & $0.791(0.316-1.98)$ & \multirow{4}{*}{ - } \\
\hline $25-29 \mathrm{yr}$ & $131(53 \%)$ & $116(47 \%)$ & $5.6(2.8-11.3)$ & $0.126(0.041-0.39)$ & \\
\hline $30-34 \mathrm{yr}$ & $25(14.3 \%)$ & $150(85.7 \%)$ & $0.83(0.384-1.8)$ & $0.28(0.07-1.05)$ & \\
\hline$\geq 35 \mathrm{yr}$ & $11(16.7 \%)$ & $55(83.3 \%)$ & 1.00 & 1.00 & \\
\hline
\end{tabular}

Respondents who had positive attitude towards hygienic complementary feeding were 4-folds (AOR: 4.01, 95\% CL: 1.9-8.5) more likely to follow hygienic practice while complementary feeding than those who had negative attitude towards hygienic complementary feeding. Respondents who had handwashing facility after toilet visit were 7-folds (AOR: 6.75, 95\% CL: 3.16-14.41) more likely to follow good hygienic practice during complementary feeding as compared with those respondents who had $\mathrm{n}$ o handwashing facility in their doorstep (Table 3 ).

\section{Discussion}

The present study showed that, out of 604 study participants, $303(50.2 \%)$ participants had separate kitchens for children, and it was lower than that found in the study conducted in Mohoni town (86\%) [19]. This difference could be due to the study setting, because the previous study was conducted the in urban community; as a result, they might have access to information related with hygiene practice and that might have helped them to have separate kitchens. 
This study showed that only 56 (9.3\%) and 54 (8.9\%) of mothers always washed their hands with soap after toileting and before feeding the children, respectively, which is lower than those of the study conducted in Bangladesh, who reported $59.2 \%$ and $43.2 \%$ mothers always washed their hands with soap after toileting and before feeding, respectively [16].

In the present study, 145 (24\%) and 123 (20.4\%) of mothers always washed their hands with soap after toileting and before eating, respectively. This study finding is lower than that of the study conducted in Hanoi, Vietnam, which revealed that $36.8 \%$ and $29 \%$ mothers always washed their hands with soap after toileting and before eating, respectively [14]. The difference might be due to the difference in the study setting, and both studies (Vietnam and Bangladesh) were performed in the cities, so the study participants might be informed on the importance of hygienic practice and the health sector might be committed to wards' hygiene and sanitation activities in both countries.

This study reported that $9 \%$ of mothers washed their hands with water and soap at critical times, and this result was supported by the study conducted in Tanzania Longido District of Arusha, in which they reported 9.3\% of mothers washed their hand with water and soap at critical times [20]. Additionally, this study finding was higher than that of the study conducted in Ghana, where only $2.3 \%$ of Ghanian mothers always washed their hands with water and soap at critical times [21]. This difference might have occurred due to the period the study was performed; a Ghana study was performed ten years ago, and the study participants might not have got adequate information related to good hygiene practices.

In the present study, 424 (70.2\%) mother washed their hands only with water before feeding the child, which is lower than that of the study conducted in India, which reported more than $90 \%$ of the study participants washed their hands with water only before and meal [18].The difference might be because of the difference in the study setting; the prior study was conducted in urban areas and also the development level of the country might have contributed to follow good hygiene practice properly. Hygienic practice during complementary feeding is affected by cultural factors, beliefs, and knowledge of parents on appropriate practices, safe preparation, and proper storage of complementary foods, which are the important determinants of proper CF practices [22]; as a result, the cultural practice and knowledge of mothers might have varied between the two countries, and this variation might have a great contribution on people's hygiene practice.

The present study illustrated that the perception or attitude of mothers was significantly associated with the hygienic practice of mothers during complementary feeding. This study finding is supported by a study in Hanoi, Vietnam [14]. In this study, latrine ownership and access to media (TV or radio) were significantly associated with the hygienic practice in complementary feeding, and the result was also supported by a study performed in Bangladesh [17]. This could due to the fact that media play a great role in disseminating information necessary to implement appropriate complementary feeding.
In the present study, the availability of handwashing facility at doorstep after toilet visit was significantly associated with hygienic practice during complementary feeding, and this finding was supported by similar studies performed in the rural parts of Bangladesh [16]. The present study showed that the residence of the study participants was significantly associated with hygienic practice during complementary feeding. Respondents who were living in urban were 5 -folds more likely to perform good hygienic practice as compared with those respondents who were living in the rural areas.

\section{Limitations of the Study}

This study was conducted at the community level, so the finding of the study could be a better representative of the source population. Despite this, social desirability bias and recall bias might be introduced while interviewing the study participants.

\section{Conclusions}

The present study showed that mothers had poor hygienic practice during complementary feeding. In this study, attitude, access to media, household private latrine ownership, presence of handwashing facility in their doorstep, and residence of the study participants were significantly associated with good hygienic practice of mothers during complementary feeding. It is recommended that the health sector shall work greatly on providing health education and training on the health consequence of poor hygienic practice during complementary feeding on their child.

\section{Data Availability}

All the relevant data used to support the study are included within the manuscript.

\section{Disclosure}

The funders had no role in the study design, data collection and analysis, decision to publish, or preparation of the manuscript.

\section{Conflicts of Interest}

The authors declare that there are no conflicts of interest regarding the publication of this paper.

\section{Authors' Contributions}

Alelign Alemu Demelash and Getachew Yideg Yitbarek designed the study, collected the data, analyzed the data, interpreted the result, and prepared the manuscript for publication. Biruk Demisse Melese conceived the study, supervised the data collection, and reviewed the proposal and the draft of the manuscript. Fitalew Tadele Admasu participated in designing the study, supervision of the research project, and reviewing of the draft of the manuscript. Enyew Tegegne Bayih participated in designing the study, 
analyzed the result, and prepared the manuscript for publication.

\section{Acknowledgments}

Firstly, we would like to acknowledge Bahir Dar University. Secondly, we would like to thank Bahir Dar Zuria District health administrators, data collectors, and study participants for their contribution during the conduction of this study. Thirdly, our heartfelt thanks go to our colleagues and intimate friends who helped and motivated us while conducting this research work.

\section{References}

[1] J. K. Kung, K. J. Boor, S. M. Ame, N. S. Ali, A. E. Jackson, and R. J. Stoltzfus, "Bacterial populations in complementary foods and drinking-water in households with children aged 10-15 Months in zanzibar, Tanzania," Journal of Health, Population and Nutrition, vol. 27, no. 1, pp. 41-52, 2009.

[2] S. M. Parvez, L. Kwong, M. J. Rahman et al., "Escherichia colicontamination of child complementary foods and association with domestic hygiene in rural Bangladesh," Tropical Medicine \& International Health, vol. 22, no. 5, pp. 547-557, 2017.

[3] R. Agustina, T. P. Sari, S. Satroamidjojo, I. M. J. Boveeoudenhoven, E. J. M. Feskens, and F. J. Kok, “Association of food-hygiene practices and diarrhea prevalence among Indonesian young children from low socioeconomic urban areas," BMC Public Health, vol. 13, no. 1, 2013.

[4] A. A. Usfar, D. N. Iswarawanti, D. Davelyna, and D. Dillon, "Food and personal hygiene perceptions and practices among caregivers whose children have diarrhea: a qualitative study of urban mothers in tangerang, Indonesia," Journal of Nutrition Education and Behavior, vol. 42, no. 1, pp. 33-40, 2010.

[5] M. S. Islam, Z. H. Mahmud, P. S. Gope, R. U. Zaman, Z. Hossain, and M. S. Islam, "Hygiene intervention reduces contamination of weaning food in Bangladesh," Tropical Medicine International Health, vol. 18, no. 3, pp. 250-258, 2013.

[6] J. H. Rah, A. A. Cronin, B. Badgaiyan, V. M. Aguayo, S. Coates, and S. Ahmed, "Household sanitation and personal hygiene practices are associated with child stunting in rural India : a cross-sectional analysis of surveys," BMJ Open, vol. 5, no. 2, 2015.

[7] L. Badriyah and A. Syafiq, "The association between sanitation , hygiene, and stunting in children under two-years (an analysis of Indonesia 's basic health research, 2013)," Journal of Health Research, vol. 21, no. 2, pp. 35-41, 2017.

[8] E. R. J. Giugliani and C. G. Victora, "Complementary feeding," Journal de Pediatria (Rio Journal), vol. 76, no. 3, pp. 253-62, 2000.

[9] J. Msuya, S. Ilic, R. Bruno, I. Hatsu, and J. Kinabo, Food Safety of Homemade Complementary Foods In Morogoro Municipality-Tanzania, The Ohio State University, Columbus, $\mathrm{OH}$ ,USA, 2016.

[10] K. G. Dewey, "The challenges of promoting optimal infant growth," The Journal of Nutrition, vol. 131, pp. 1879-1880, 2001.

[11] G. Jones, R. W. Steketee, R. E. Black, Z. A. Bhutta, S. S. Morris, and C. Survival, "How many child deaths can we prevent this year?” The Lancet, vol. 362, no. 9377, pp. 65-71, 2003.
[12] F. Saleh, F. Ara, A. Hoque, and S. Alam, "Complementary feeding practices among mothers in selected slums of dhaka city: a descriptive study," Journal Health Population and Nutrition, vol. 34, no. 1, pp. 89-96, 2014.

[13] K. S. Imtiaz, K. Begum, N. Begum et al., "Practice of personal hygiene among rural women of a selected community in Bangladesh," Northrn International Medical College Journal, vol. 6, no. 1, pp. 29-31, 2014.

[14] K. Takanashi, Y. Chonan, D. T. Quyen, and N. C. Khan, "Survey of food-hygiene practices at home and childhood diarrhoea in Hanoi , Viet Nam," Journal of Health, Population Nutrition, vol. 27, no. 5, pp. 602-11, 2009.

[15] Y. Children, L. B. Zeleke, and M. W. Gebremichael, “Appropriate weaning practice and associated factors among infants and appropriate weaning practice and associated factors among infants and young children in Northwest Ethiopia," Journal of Nutrition and Metabolism, vol. 2017, pp. 1-7, 2017.

[16] S. P. Luby, S. Akhter, R. B. Johnston, A. K. Halder, C. Tronchet, and A. Bhuiya, "Household characteristics associated with handwashing with soap in rural Bangladesh," The American Journal of Tropical Medicine and Hygiene, vol. 81, no. 5, pp. 882-887, 2009.

[17] S. E. Rabbi and N. C Dey, "Exploring the gap between hand washing knowledge and practices in Bangladesh: a crosssectional comparative study," BMC Public Health, vol. 13, no. 1, p. 1, 2013.

[18] B. Venkatashiva Reddy, Y. S. Kusuma, C. S. Pandav, A. K. Goswami, and A. Krishnan, "Water and sanitation hygiene practices for under-five children among households of sugali tribe of chittoor district, Andhra Pradesh, India," Journal of Environmental and Public Health, vol. 2017, pp. 1-7, 2017.

[19] A. Living, Y. Children, N. Eastern, G. Yitayih, K. Belay, and M. Tsegaye, "Assessment of hygienic practice on complementary food among mothers assessment of hygienic practice on complementary food among mothers with 6-24 Months age living young children in Mohoni town, North eastern Ethiopia, 2015," Journal of Immunology, vol. 6, no. 1, pp. 1-7, 2015.

[20] H. A. Mshida, N. Kassim, M. E. Kimanya, and E. Mpolya, "Influence of water, sanitation, and hygiene practices on common infections among under-five children in longido and monduli districts of Arusha, Tanzania," Journal of Environmental Public Health, vol. 2017, pp. 1-18, 2017.

[21] B. Scott, V. Curtis, T. Rabie, and N. Garbrah-Aidoo, "Health in our hands, but not in our heads: understanding hygiene motivation in Ghana," Health Policy and Planning, vol. 22, no. 4, pp. 225-233, 2007.

[22] WHO, Infant and young child feeding, WHO, Geneva, Switzerland, 2020. 